Recepción: 16 / 02 / 2018

Aceptación: 28 / 03 / 2018

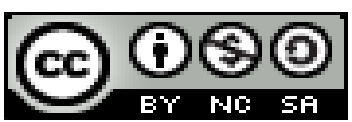

Artículo de Revisión

Publicación: 21 / 05 / 2018

\title{
La metacognición personal en la programación arquitectónica: Hacia la conciencia en el diseño
}

\section{Personal metacognition in architectural programming: Towards consciousness in design}

\section{Metacognição pessoal em programação arquitetônica: Rumo à conscientização do design}

Erick Bojorque-Pazmiño I

jorge.bojorque@uleam.edu.ec

Alexis J. Macías-Loor II

alexis.macias@uleam.edu.ec

Héctor Cedeño-Zambrano III

hector.cedeno@uleam.edu.ec

Correspondencia: jorge.bojorque@uleam.edu.ec

II. Arquitecto MG; Docente Facultad de Arquitectura; Universidad Laica Eloy Alfaro de Manabí, Manta, Ecuador. 


\section{Resumen}

Situación compleja y difícil el articular un proceso de programación arquitectónica que trata de alguna manera, el llevar adelante un evento creativo que es completamente resultado de la libre iniciativa y la libertad del que no teme. El creativo jamás podría encasillar su consciencia a un método científico, eso sería como tratar de contener el cielo en una botella. La creatividad es sin duda un funcionalismo del Ser y la esencia de quién es capaz de manifestarla, pero nunca de un proceso sistemático. Una cosa es el instante de luz y otra el sendero que nos permite detenernos para lograr el instante.

En estos apuntes no pretendemos cercar la consciencia ni la creatividad del arquitecto, sino queremos entregar una postura al recopilar de datos que le permitan acercarse a ese momento de genialidad que es la escena misma de la creatividad.

Palabras clave: Metacognición; Programación; Arquitectura; Planificación; Consciencia. 


\begin{abstract}
Complex and difficult situation to articulate a process of architectural programming that deals in some way, to carry out a creative event that is completely the result of the free initiative and the freedom of the one who does not fear. The creative could never pigeonhole his conscience to a scientific method, that would be like trying to contain the sky in a bottle. Creativity is undoubtedly a functionalism of the Being and the essence of who is capable of manifesting it, but never of a systematic process. One thing is the moment of light and another the path that allows us to stop to achieve the moment.

In these notes we do not intend to surround the conscience nor the creativity of the architect, but we want to give a position to collect data that allows us to approach that moment of genius that is the scene of creativity itself.
\end{abstract}

Keywords: Metacognition; Programming; Architecture; Planning; Consciousness. 


\section{Introducción.}

\section{Secuencia de eventos investigativos en la programación arquitectónica.}

La programación arquitectónica es un hecho tal como lo es la estética y que como ella "ha partido de la investigación filosófica que en esencia es la búsqueda de la verdad" (Bojorque, 2017: 25) contenida en un evento exterior que para el caso de lo estético viene dado por la percepción sensible de un instante dado en el evento y en la programación arquitectónica por la minuciosidad en la recopilación de evidencias y datos sobre ese evento. La estética tiene expresión material que induce la verdad, mientras que la programación se expresa materialmente en el diseño.

Encarar el diseño arquitectónico es una tarea que encumbre múltiples acciones y factores que el arquitecto ha de dilucidarlos según la pertinencia de su formación y las condiciones del encargo que se le ha encomendado. Este es un proceso individual y personal y que conlleva la esencia del pensamiento del compositor en su expresión más rigurosa de análisis.

El arquitecto está llamado a la creación pero como profesional también está llamado a tecnificar su acción en procesos más o menos cuantificables que le acercan sutilmente a eso que se convertirá en el hecho arquitectónico. Este cúmulo de eventos viene de resultas en la programación arquitectónica, la que expresándose materialmente no es, sino la verdad ínfima de un instante histórico y personal pero que lleva en sí la esencia de una gran verdad relevante. Juhani Pallasmaa nos dice hablando de Andréi Tarkovski: 
"La imagen no es aquel sentido expresado ahí por el director, sino todo un mundo que se refleja como en una gota de agua" (Pallasmaa, 2016: 65)

Cuando al arquitecto se le encarga la creación de un nuevo ser edificado, este se encuentra frente a grandes interrogantes que le suponen grandes conflictos y a la vez increíbles respuestas. Estos conflictos tienen que ver con el conocimiento de lo encomendado, de quienes lo han planteado, de para quienes ha de servir y de toda su implicancia con respecto al lugar en el que ha de ser emplazado y de su incidencia en el modo urbano y social de aquel entorno.

Por ello el arquitecto no simplemente se encarama en su tablero de trabajo para componer el nuevo objeto arquitectónico como si de elucubrar se tratara. El proceso de diseño no puede empezar sin un conocimiento previo detallado de las interrogantes de diseño, pues en su misma manifestación se delatarían las falencias al no poder precisar, por ejemplo, el tamaño de la zona de hospitalización de un centro de salud sin saber el número de camas requeridas; o el tamaño de la sala de la vivienda del magnate que usa sillones tan variados como son sus amistades.

La realidad de la creación se haya sin lugar a dudas en la genialidad de un acto pero, ese acto que se bocetee o se esgrime para hacerse efectivo, ha de tener la suficiencia en datos como para definirlo. ¿Qué hubiera sido de la cruz con traverso en senoide que Lucio Costa trazara para concretar lo que sería Brasilia sin el pliego de información, rubros, estadísticas que una ciudad conlleva? Solamente un gesto inspirador. 


\section{Imagen 1.- Plano piloto urbano de Brasilia por Lucio Costa}

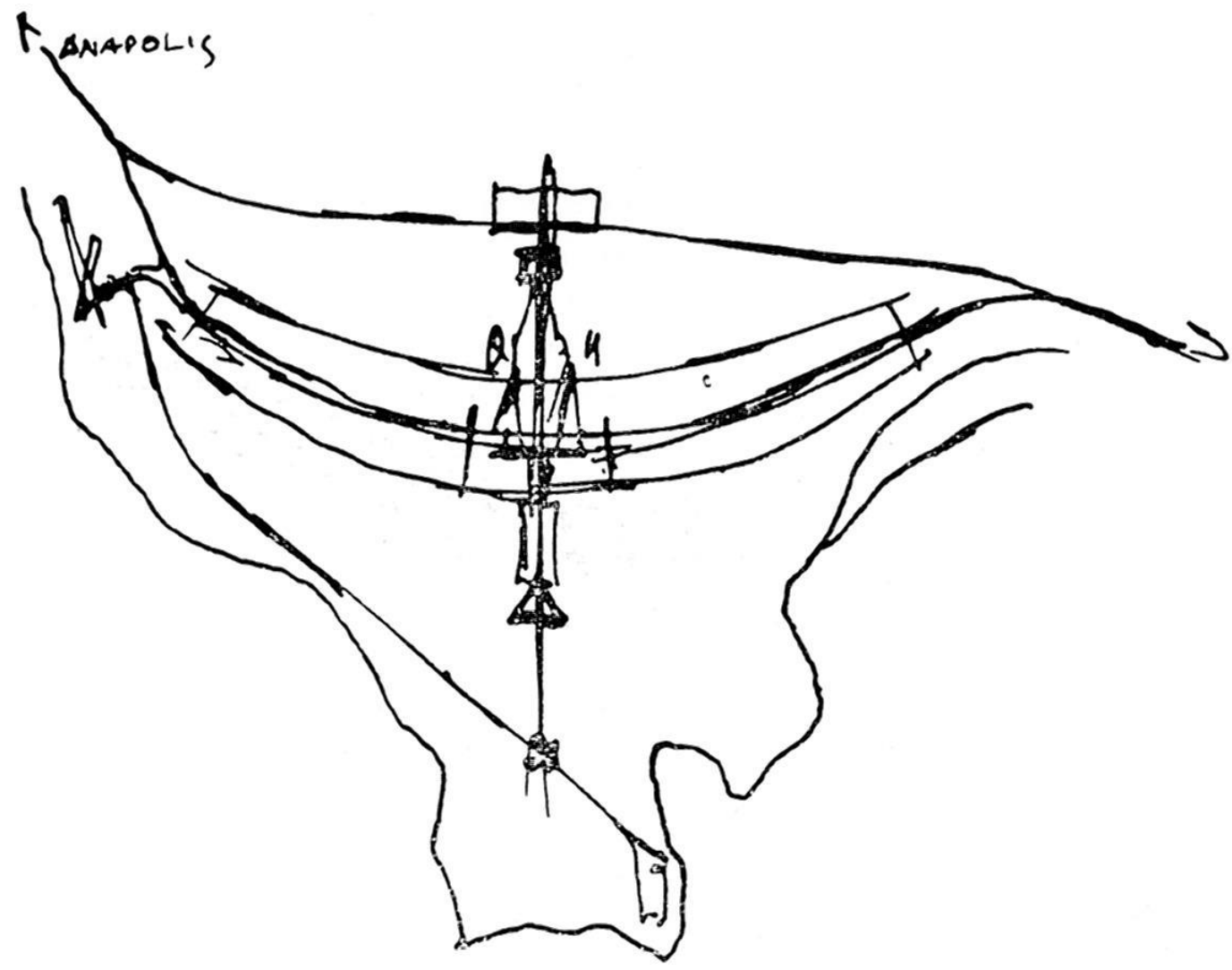

Fuente: Imagen tomada de la Internet

Como vemos en la <Imagen 1> la creatividad expresada por genialidad acomete repentinamente en el espectro material y se expresa en un boceto que el arquitecto Costa lo sintetizó magistralmente, pero sin la información pertinente de lo que sería en ese entonces, año 1957, la ciudad de Brasilia, esta idea se hubiera mantenido en un hecho etéreo inmaterial simplemente. Lo que llevó a su cristalización fueron justamente los datos surgidos de una intensa programación. Con esto no queremos llevar nuestra voluntad hacia una simpatía con el gesto urbano de Costa, a todas luces envuelto en pensamiento racional, cuyo derrotero es la inconsciencia del manejo a la usanza universal de la condición humana; pero su planteamiento 
nos permite ilustrar el primer instante creativo sopesado por la postura personal, en este caso de corte moderno.

Este proceso de creación necesita de un método que debe acomodarse a la especificidad del arquitecto, pues es él, el centro de toda la composición edilicia. Si el arquitecto es una persona poco versada y con poco dominio de su propia naturaleza, la composición tendrá esas características también. Por el contrario, si el arquitecto se auto edifica en el sentido de mejorar su percepción sensible desde las impresiones físicas que recibe a través de sus cinco sentidos resolviéndose comprender el mundo paradigmático en el que vivimos y se compromete con su profesión que versa siempre como una labor de engrandecimiento y sanidad de las personas usuarios, entonces su composición tendrá la relevancia que el mundo de hoy amerita. El método entonces debe garantizar el por lo menos cubrir con las expectativas que el creativo requiere.

El arquitecto sensibilizado ante sí, en su proceso de conocimiento ha de incluir en su comprensión de los eventos relacionados al hecho arquitectónico las demás ciencias solidarias con la materialidad espacial arquitectónica como son aquellas sociales, lógico-formales, filosóficas, estéticas, que aportan efectivamente luces al compromiso de la arquitectura con la comunidad y la sociedad; pues un hecho arquitectónico no solamente es una obra acabada en sí y para sí sino que como una persona cualquiera influye en sus cercanos y en los que están fuera de él. Pedro Azara aclara tal aseveración elevando a nivel de arte a la arquitectura, la que venida a menos durante el siglo XX en único conocimiento constructivo, pasó de ser expresión material consciente a resultas de un efecto técnico. 
"Entre los fines que el arte persigue o permite, se halla una exploración, una interrogación, una reflexión sobre el espacio habitado: sobre la habitabilidad del mismo, sobre cómo vivimos, cómo nos hacemos con un espacio, sobre qué lugar nos pertenece, qué lugar ocupamos; finalmente, porqué ocupamos un lugar, es decir, sobre nuestra presencia en el mundo. La arquitectura es el arte de pensar esa relación” (Azara, 2015: 16)

La programación arquitectónica cabe en todas estas interrogantes, no como efecto ni como delator de soluciones, sino como un crisol que recopila lo que la investigación ha decantado desde la perspectiva de varios orígenes científicos sin ser ellos la esencia de la misma.

Esta indagación y empatía del arquitecto con otras ciencias no ha de determinar una influencia definitiva en la composición creativa, sino que acompañan y ayudan, evitando "el metodismo en el proceso de diseñar o la aberrante investigación" que lo que hacen es "la supresión lisa y llana de la práctica efectiva del diseño, una bastardización del objeto diseñado resentido en sus aspectos más esenciales. En suma, el hecho arquitectónico enfocado como “subproducto" de procesos” (Rodríguez, 1999: 13)

La programación arquitectónica por tanto es todas aquellas acciones que enfrentando el conocimiento del arquitecto con respecto de sí y del encargo que le ha sido confiado, le permiten los datos y las herramientas para por libre iniciativa crear un nuevo evento arquitectónico que será entregado al mundo. Esta programación depende del propio arquitecto, por lo que cada arquitecto debería en el transcurso de su praxis profesional enfocar y acicalarse con una que le sea adecuada, consciente y favorable a sus atributos. 
Distinto es aquel que pretendiendo magnificencia en sus diseños toma por sorpresa el encargo y lo convierte en un mero formalismo de elucubraciones compositivas, haciendo de la práctica profesional aquello que es detestable e impositivo y que caracteriza como lo dice Nietzsche a las razones de espantapájaros:

“...cargados de pre-razones y post-razones que a ningún pie le es posible recorrer hasta el final, ocultos bajo los mantos de la luz, conquistadores aunque parezcamos herederos y derrochadores, clasificadores y coleccionadores desde la mañana a la tarde, avaros de nuestras riquezas y de nuestros cajones completamente llenos, parcos en el aprender y olvidar, hábiles en inventar esquemas, orgullosos a veces de tablas de categorías, a veces pedantes, a veces búhos del trabajo, incluso en pleno día; y, si es preciso, incluso espantapájaros." (Nietzsche, 2007: 48)

La razón y sus distintas posturas no convienen ciertamente a un programa arquitectónico que diste de ser un esquema inventado y un superfluo enredo de datos. La postura del arquitecto consciente no se versa en la clasificación, ni en el esquema, ni es su sostén el método como tal, sino la relevancia que los datos encontrados por el método, puedan aportar, acorde con su postura personal o metacognición, a la adecuada manifestación y posterior expresión material de la edificación. De esta manera un proyecto cualquiera se enriquece de la individualidad de cada postulante del encargo. Un arquitecto con consciencia minimal compilará datos que serán diferentes y distintos a los de un arquitecto bioclimático. Esta divergencia enriquece y no mansilla como lo ha hecho la universalización moderna. 
Una metodología sin querer ser impositiva o conquistadora ha de dar visos de consciencia en el arquitecto, aparatándolo de los enunciados racionales modernos que someten al creativo en una secuencia imparable de dogmas metódicos y que lo encasillan en la generalización, la modulación, la prefabricación y la imitación comercial; para por el contrario, hacer detallada su investigación, que mira en la partición cognitiva, una manera adecuada para conocer la verdad de lo investigado; sin querer con ello convertir el proceso en la creación misma de la composición, enriqueciendo por el contrario dicha iniciativa con datos consecuentes a tal acto creativo, resultado de una secuencia de eventos investigativos, cuyo principal actor es el arquitecto y su metacognición personal.

\section{Cuadro 1.- Secuencia de eventos investigativos arquitectónicos}

\section{EL ENFOQUE PERSONAL}

LOS ANTECEDENTES DEL ENCARGO

EL DIAGNÓSTICO DE OBRAS EXISTENTES RELACIONADAS

LA PROGNOSIS DE OBRAS EXISTENTES RELACIONADAS

LA IMAGEN OBJETIVA DEL PROYECTO

EL PROGRAMA ARQUITECTÓNICO

EL PROYECTO ARQUITECTÓNICO POR ÓRDENES COGNITIVOS

EL HECHO ARQUITECTÓNICO SOCIAL 
Fuente: Elaboración del autor

\section{El enfoque personal en la programación arquitectónica: La metacognición.}

El arquitecto es el centro en la composición arquitectónica pues, es él, el transductor de la vorágine creativa que atrapa del mundo de lo inconmensurable las verdades comprendidas luego como soluciones idóneas para y en el proyecto. Esta postura es contraria a aquellas visiones estoicas que encumbran las necesidades como elemento primordial en el diseño. Resulta ancestral y hasta lejano a nuestro entendimiento las carencias de Violet Le Duc con respecto a que el programa de necesidades es lo real de un proyecto. La necesidad es la razón del proyecto pero la relevancia con la que es resuelta, es lo que convierte a una obra en adecuada. La necesidad en sí no nos dice nada, la postura ante ella nos permite maestría. El arquitecto ha de tener en su vida profesional un modo particular de encarar los procesos de creación entre los que se encuentra de manera esencial la metacognición con la que se apropia del conocimiento y la creatividad.

Los aspectos cognitivos dilucidan y hacen comprensible los funcionalismos mentales al momento de convertirse estos en una expresión material, vocal o no, y que de esta manera permiten la trascendencia del conocimiento obtenido ese instante y, sobre la marcha, de éste en los restantes procesos de aprehensión que se convierten en aprendizaje particular o metacognición.

"El iniciador de la teoría cognitiva en Europa fue John Flavell, quien en 1977 dio a conocer El Desarrollo Cognitivo, en tanto que tres años más tarde los norteamericanos Linda Flower y John Hayes publicaron A Cognitive Process Theory of Writing. El objeto de estos investigadores eran los mecanismos internos de la 
mente que se activan durante el uso del lenguaje, que pueden ser verbalizados, y a los cuales se puede acceder, consecuentemente, por la información que de sí mismos dan los sujetos, mientras realizan una tarea que es grabada.” (Mostacero, 2013: 172)

La metacognición del arquitecto es su particular sistema de aprehensión del conocimiento que se traduce en su personal cuestionamiento de a dónde quiere llevar sus propuestas desde una postura macro que le permita encarar cualquier encargo sea del tipo que sea y las particulares maneras de aprender sobre lo mismo cada vez, en espiras superiores y trascendentes. En la metacognición hay una secuencia que empezando por inquietud, pasa por conocimiento, aprendizaje, trascendencia, relevancia, para llegar nuevamente a una inquietud cuestionadora.

Pero, la metacognición es siempre relevante y auto edificante y se distingue de los meros principios casuísticos. Vemos como los cinco principios de la arquitectura racionalista postulados por el arquitecto suizo Le Corbusier, guiaron por más de 30 años los diseños y soluciones de “edificaciones máquina” a los arquitectos modernos del siglo XX, siendo el mismo Le Corbusier quién abandonó su postura por irrelevante.

La metacognición es esa manera como el compositor se apropia del conocimiento y como aprende mientras crea, en un proceso de ida y vuelta cognitivo y práctico.

Si el arquitecto no tiene un norte o un destino, si así podemos decirlo, sus propuestas no tendrán la trascendencia propia ni la relevancia que el mundo espera de todo hecho arquitectónico, como la humanidad espera de cada uno de sus miembros. Ese destino es su particularidad concebida tanto en las íntimas reflexiones como en la manera natural de expresar sus modos creativos. 
Los modos creativos son tales para cada arquitecto que serán decidores en su obra y que se delatan en su propio estilo particular. Es innegable que las obras del arquitecto inglés Sir Norman Foster son reconocidas fácilmente por su tecnología humanista; o las del arquitecto moderno finlandés Alvar Aalto por su identidad y preocupación por el contexto. Cada arquitecto relevante tiene su propia naturaleza expresada materialmente delatando su metacognición generatriz.

Sería muy inadecuado y hasta pueril que un arquitecto tuviera el coraje de presentar varias propuestas de distinta índole con respecto de un encargo para definirlo, casi tan absurdo como que un galeno presentara varias recetas médicas y distintas posologías a su paciente para que él las escoja. ¡Absurdo! Pero, resulta que en la escena profesional los arquitectos si se atreven a convertir y a reducir su labor a un simple escoger, a un falseamiento intrínseco de la verdad contenida en el propósito de diseñar, para que sean los usuarios de la obra los que disipadamente decidan cuál ha de ser la propuesta adecuada, relegando su responsabilidad y criterio a una secuencia de gusto y apariencia, una suerte de sancta simplicitas como lo dijera en su tiempo Nietzsche.

“O sancta simplicitas! ¡Dentro de que simplificación y falseamiento tan extraños vive el hombre! ¡Imposible resulta dejar de maravillarse una vez que hemos acomodado nuestros ojos para ver tal prodigio! ¡Cómo hemos vuelto luminoso y libre y fácil y simple todo lo que nos rodea!, ¡cómo hemos sabido dar a nuestros sentidos un pase libre para todo lo superficial; y a nuestro pesar, un divino deseo de saltos y 
paralogismos traviesos!, ¡cómo hemos sabido desde el principio mantener nuestra ignorancia, a fin de disfrutar una libertad, jovialidad apenas comprensibles de la vida, a fin de disfrutar la vida! (Nietzsche, 2007: 30)

Esa es la jovialidad del creador y del compositor sin norte, sin el sentido decoroso de la propia convicción sobre algo, que navega sin rumbo por entre las aguas intrincadas de la indecisión y del sin saber; esa jovialidad que se revuelve entre la especulación de la forma, la belleza que induce moralidad y de los aspavientos de quién hace lo que todos han hecho, que no puede esperar sino la aprobación gentil del seducido y el acompañamiento de los que copian.

Un arquitecto con toda la formación que ha recibido y que sigue recibiendo durante toda su vida, debe saber que es el más preparado y capacitado para enfrentar problemas edilicios, urbanos, etc., sin con ello caer en la arrogancia, pero con atributos necesarios para guiar y ayudar a los seres humanos y entregarles verdaderos templos de sanidad, abundancia, alegría y prosperidad; y que, comete error al devaluarse y convertir su magnífica labor en una serie de eventos formales de propuestas innecesarias que lo único que delatan es falta de auto estima y de una metacognición clara.

Un arquitecto que se auto edifica tendrá necesariamente distancia de quién sirve a los defectos personales en su labor. Luis Racionero nos explica cómo cada postura y actitud personal ante un encargo, en este caso artístico, definirá un resultado en su obra:

"Por lo tanto, cuando un artista se dedica perezosamente a su trabajo y no logra dibujar desde lo más profundo de su alma, su pintura es débil y blanda y carece de decisión. Su falta es la de no concentrarse en lo esencial. Si está confundido y tiene 
ideas nebulosas, entonces las formas se tornan oscuras e inciertas. Su falta es la de no poner toda su alma en su trabajo. Si se aproxima a su pintura demasiado livianamente, entonces las formas probablemente serán desarticuladas e inarmónicas. Su falta es la carencia de dignidad. Si descuida su trabajo por engreimiento, la composición resulta descuidada e incompleta. Su error es la falta de diligencia. Por lo tanto, la indecisión conduce a un análisis defectuoso, la confusión a una carencia de elegancia, lo desarticulado a una falta de proporción, lo incompleto a una carencia de composición ordenada. Éstas son las mayores faltas del artista. Estos asuntos, sin embargo, sólo se pueden discutir con personas que han visto la luz.” (Racionero, 2016: 81)

Un hecho arquitectónico es una obra tal que no puede tomarse a la ligera ni ser el resultado de un evento egoico que al ser realizado se convierte en disonante con la escena material en donde se desarrolla, convirtiendo hermosas praderas en ciudadelas conflictivas y desagradables; tranquilos lugares en fuentes de agresión y desencanto y calles solariegas en líneas de muerte y destrucción. Una obra se merece arquitectos entregados a su labor y a su edificación personal.

Esta edificación personal empieza definiendo en el arquitecto para sí una postura propia y particular que le permitirá guiar su proceso creativo con la insignia de una identidad dada, por sobre la cual no existirá sino su propia valía como arquitecto, alejándolo de la incertidumbre del que está sujeto a los vaivenes de los paradigmas sociales de la imitación, la coacción y el miedo. 
Esta postura propia es la metacognición personal del arquitecto quien recurriendo a su vocación dilucida entre sus vivencias aquello que es su nota clave de vida y labor. Un arquitecto no es un ente aislado ni el resultado único de la educación académica o práctica, sino que es la suma aritmética de experiencias más o menos conscientes que de alguna manera le llevaron al sitial donde se desenvuelve y a su manifestación material.

Estas vivencias marcan derroteros importantes en su devenir. Tal vez el contacto con un profesional arquitecto trascendente o con una obra maestra o con un simple detalle relevante le permitió rozar y hasta tocar de lleno con su esencia vocacional siendo inducido hacia la bella profesión. Este evento se convierte en el primer detonante de lo que podríamos llamar el principio de manifestación arquitectónica y que es el punto de partida de la metacognición personal. Es decir un arquitecto podría encumbrar en su postura a la reticencia; otro a lo sensible; estotro a lo monumental. De resultas la arquitectura se enriquecería por la existencia de miles de arquitectos y miles modos de comprenderla y manifestarla y no de unas pocas tendencias, convincentes o no, con miles de seguidores.

Un hecho engrandecedor para la humanidad son los profesionales vocacionales que auto conociéndose proponen desde su interior comprendido, obras relevantes arquitectónicas.

Pero, el arquitecto ha de proponer también materialmente. La estética y el estilo son necesarios para este evento. La metacognición se nutre del interior del arquitecto pero necesita también de un estilo pertinente y el profesional ha de tomar en consideración aquello.

La estética es la búsqueda de la verdad a través de la percepción sensible. El arquitecto con plena atención puede encontrar una estética para cada situación. Si esta estética resulta en 
elementos compositivos que se repiten, entonces es su estilo lo encontrado. Este acto aquí manifestado es relevante y trascendente y puede o no darse en toda la vida del arquitecto. Pero, las obras no están para esperar este momento cosmológico. Nos interesa entonces conminar a la definición sensorial subjetiva de un estilo que más se acople a lo que es la vivencia fuente vocacional del arquitecto.

Los estilos históricos son una fuente inagotable y adecuada para su uso en la arquitectura. Así un arquitecto con principio reticente puede definir la expresión material de sus obras con estilo internacional por cuanto el arquitecto reticente busca la inducción de la consciencia en el usuario y la geometría y la plástica se acoplan a ello perfectamente. Otro principio de contemplación podría usar el estilo minimalista para su expresión material. Por ejemplo.

\section{Cuadro 2.- La metacognición personal: Principio vocacional y estética}
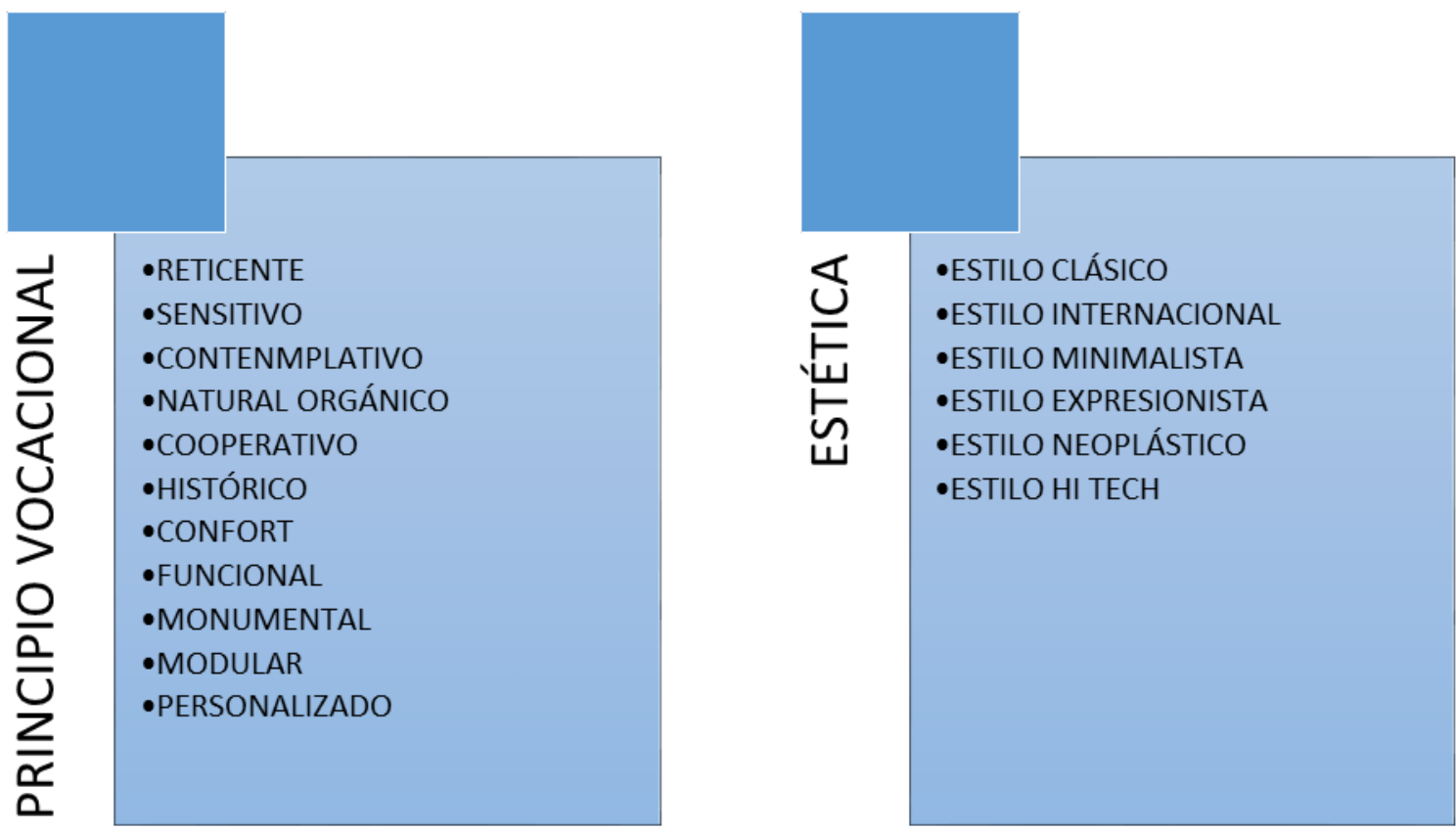
Fuente: Elaboración del autor

Lo interesante de establecer una postura metacognitiva, no es la postura en sí, sino el enrumbamiento que ella permite a la embarcación del diseño por el océano cognitivo, logrando de esta manera componer una parte del todo infinito de posibilidades que como le decimos no interesa tanto como el definirse por una dirección que será para el arquitecto perdurable o enjuiciable en el tiempo.

\section{Imagen 2.- Metacognición personal}

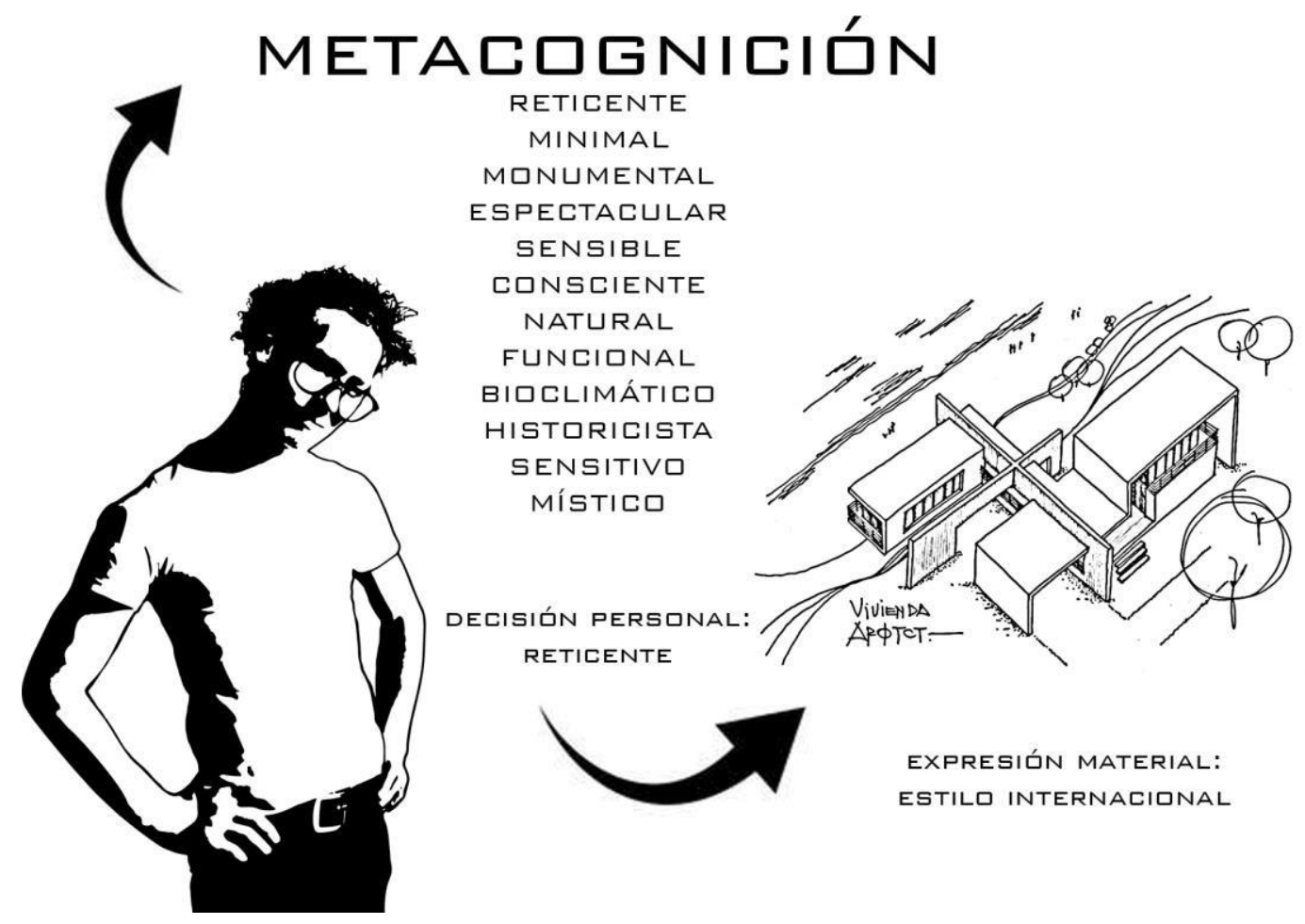

Fuente: Elaboración del autor 
En su vida profesional el arquitecto como es natural y adecuado, migrará de metacognición y de expresión material de ella, sin perjuicio de su profesión sino evidentemente enriqueciendo sus proyectos y realizaciones, permitiendo con ello y a partir de ello una auto edificación que redundará en beneficio de la propia colectividad.

\section{La recopilación de datos.}

Como hemos visto el arquitecto versado en su vocación y definido en un estilo tiene todas las posibilidades de enfrentar el sendero de la investigación metodológica, que no nos ocupa en este artículo, desde una postura personal y por tanto enriquecedora.

No es lo mismo encarar un diagnóstico, por ejemplo, desde la perspectiva minimalista que desde lo bioclimático. Cada profesional tendrá aportes significativos en su crisol documental, mucho más adecuado y valedero que la simple suma de datos que una encuesta general permite.

Sobre una misma edificación, sobre un mismo proyecto, varios arquitectos con metacognición definida, lograrán descubrir la intrincada gama de situaciones de las que éste está hecho, dando muy posiblemente a luz, paradigmas errados constructivos, funcionales, sociales, que sirvan de base para el estudio y posterior planteamiento de mejores modos de vida para la humanidad.

\section{Bibliografía.}

Azara, P. (2015). Cuando los arquitectos eran dioses. Madrid: Catarata.

Bojorque, E. (2017). Hacia un estilo estético en la arquitectura: La Reticencia. Manta. Casa Editora Del Polo. Impreso. 
Mostacero, R. B. (2012). Construcción de la reseña crítica mediante estrategias metacognitivas. Obtenido de:

http://www.scielo.org.co/pdf/leng/v41n1/v41n1a08.pdf

Nietzsche, F. (2007). Más allá del bien y del mal. Buenos Aires: Gradifco. Impreso.

Pallasmaa, J. (2016). Habitar. Madrid: Gustavo Gil. Impreso.

Racionero, L. (2016). Textos de estética taoísta. Madrid: Alianza Editorial. Impreso. Tercera edición.

Rodríguez, J. P. (1999). LA PROGRAMACION ARQUITECTONICA: Interpretación y pautas para su tratamiento en procesos de diseño académicos. Obtenido de: http://cybertesis.uni.edu.pe/bitstream/uni/4514/1/rodriguez_jj.pdf 